See Article page XXX.

\section{Commentary: Tiered referral network for endocarditis: Will it improve surgical outcomes?}

\author{
Donald D. Glower, MD
}

Squires and colleagues ${ }^{1}$ present analysis of 513 patients undergoing surgery for infective endocarditis (IE) at 8 hospitals. The authors conclude that patients undergoing valve surgery for IE are at increased risk for operative mortality at primary valve centers as compared with comprehensive valve centers (Figure 1) and that referral or transfer of patients with IE and surgical indications to comprehensive valve centers should be considered.

This paper may be the first to evaluate the recent guidelines ${ }^{2}$ proposing a tiered system of comprehensive versus primary valve centers. This retrospective analysis does tend to support the hypothesis that a tiered system could potentially improve outcomes from patients undergoing surgery for acute endocarditis. The presented data do show that comprehensive valve centers did have better operative mortality and patient survival than did primary valve centers. However, as the authors admit, an alternative interpretation of the data might be that endocarditis (like degenerative mitral valve disease or aortic disease) has better surgical outcomes at greater-volume hospitals. Referral networks have been proposed for degenerative mitral valve disease, aortic disease, congenital heart disease, and other disease processes that are less common in the community as a whole. Whether endocarditis is different from other less common medical diseases that can benefit from volume and experience is not clear. It has been shown that, in general, the mortality benefit of hospital volume is greatest in

\footnotetext{
From the Department of Surgery, Duke University Medical Center, Durham, NC. Disclosures: The author reported no conflicts of interest.

The Journal policy requires editors and reviewers to disclose conflicts of interest and to decline handling or reviewing manuscripts for which they may have a conflict of interest. The editors and reviewers of this article have no conflicts of interest.

Received for publication Sept 16, 2021; revisions received Sept 16, 2021; accepted for publication Sept 16, 2021

Address for reprints: Donald D. Glower, MD, Department of Surgery, Duke University Medical Center, Box 3851, DUMC, Durham, NC 27710 (E-mail: glowe001@ mc.duke.edu ord.glower@dm.duke.edu).

J Thorac Cardiovasc Surg 2021; $: 1-2$

$0022-5223 / \$ 36.00$

Copyright (C) 2021 by The American Association for Thoracic Surgery

https://doi.org/10.1016/j.jtcvs.2021.09.030
}

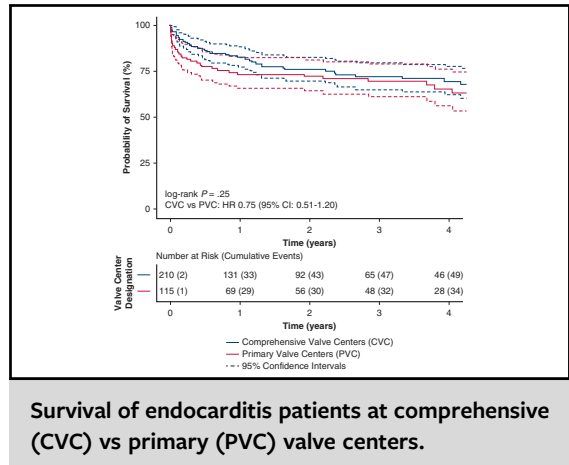

CENTRAL MESSAGE

While data support referral or transfer of patients with surgical endocarditis to comprehensive valve centers, further investigation is needed to actually demonstrate practicality and efficacy.

low-volume and high-complexity procedures. $^{3}$ Other studies have specifically shown a link between hospital volume and operative mortality for endocarditis. ${ }^{4}$

This paper has several limitations. First, this study does not address the many issues involved with implementation of such recommendations. Potential barriers to the triage of patients with endocarditis can include geographic distances, patient refusal to transfer, enforcement, and economic impact on both comprehensive and primary hospitals and staff. Second, this paper admits that it does not validate the criteria proposed for comprehensive versus primary valve centers. The 2 comprehensive centers chosen in the study may in fact differ from primary centers in many characteristics, such as simple size, volume, and seniority of staff beyond expertise in endocarditis surgery. Third, this paper does not in fact demonstrate that the implementation of recent guideline recommendations ${ }^{2}$ would indeed improve outcomes.

While these data are not definitive, they may be among the first to specifically address recent guidelines recommending a tiered system of comprehensive versus primary valve centers for treatment of acute endocarditis. ${ }^{2}$ This reasonably sized series does support a tiered referral network for surgical endocarditis. However, further investigation is needed to actually demonstrate practicality and efficacy. 


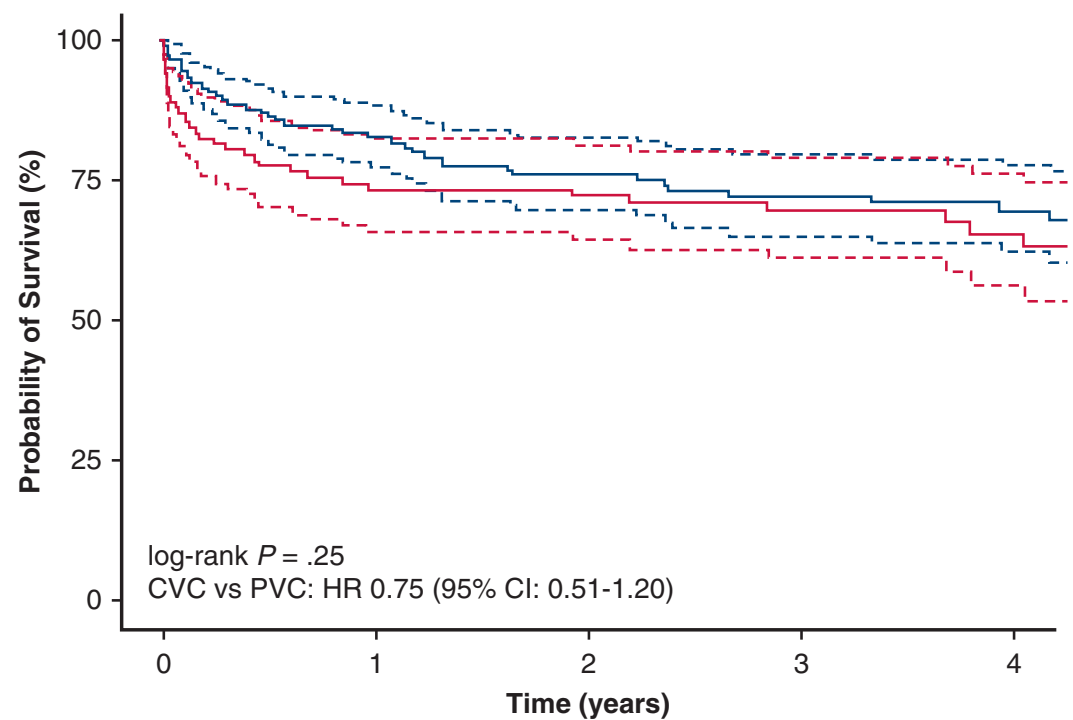

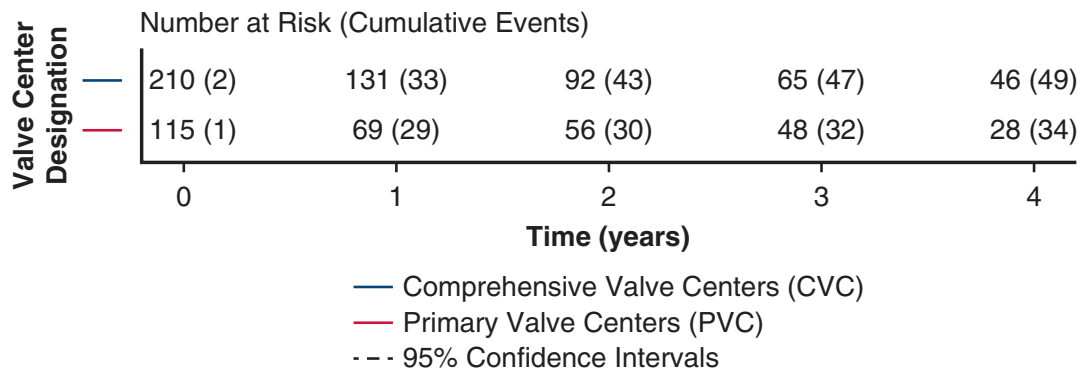

FIGURE 1. Survival curves for matched patients undergoing surgery for active endocarditis at comprehensive valve centers (CVC; blue line) versus primary valve centers (PVC; red line). HR, Hazard ratio; 95\% CI, 95\% confidence interval.

\section{References}

1. Squiers JJ, DiMaio JM, Banwait JK, Mack MJ, Ryan WH, the Baylor Scott \& White Surgery for Endocarditis Working Group, et al. Surgical treatment of infective endocarditis at comprehensive versus primary valve centers. J Thorac Cardiovasc Surg. September 18, 2021 [Epub ahead of print].

2. Nishimura RA, O'Gara PT, Bavaria JE, Brindis RG, Carroll JD, Kavinsky CJ, et al; Writing Committee. 2019 AATS/ACC/ASE/SCAI/STS expert consensus systems of care document: a proposal to optimize care for patients with valvular heart disease: a joint report of the American Association for Thoracic Surgery, American
College of Cardiology, American Society of Echocardiography, Society for Cardiovascular Angiography and Interventions, and Society of Thoracic Surgeons. J Thorac Cardiovasc Surg. 2019;157:e327-54.

3. Birkmeyer JD, Siewers AE, Finlayson EV, Stukel TA, Lucas FL, Batista I, et al. Hospital volume and surgical mortality in the United States. N Engl J Med. 2002;346:1128-37.

4. Slaughter MS, Badhwar V, Ising M, Ganzel BL, Sell-Dottin K, Jawitz OK, et al. Optimum surgical treatment for tricuspid valve infective endocarditis: an analysis of the Society of Thoracic Surgeons national database. J Thorac Cardiovasc Surg. 2021;161:1227-35. 